\title{
Determination of the Representative Elementary Volume for the Study of Sandstones and Siltstones by X-Ray Microtomography
}

\author{
Jaquiel Salvi Fernandes ${ }^{\text {**, Carlos Roberto Appoloni }}{ }^{\mathrm{b}}$, Celso Peres Fernandes ${ }^{\mathrm{c}}$ \\ anstituto Federal de Educação, Ciência e Tecnologia Catarinense - IFC, \\ Campus Videira SC-303, Km 5, Campo Experimental, CEP 89560-000, Videira, SC, Brasil \\ ${ }^{\mathrm{b}}$ Laboratório de Física Nuclear Aplicada, Departamento de Física, \\ Universidade Estadual de Londrina - UEL, CP 6001, CEP 86051-990, Londrina, PR, Brasil \\ ${ }^{\mathrm{C}}$ Laboratório de Meios Porosos e Propriedades Termofísicas, Departamento de Engenharia Mecânica, \\ Universidade Federal de Santa Catarina-UFSC, CP 476, CEP 88040-900, Florianópolis, SC, Brasil
}

Received: October 14, 2011; Revised: May 14, 2012

\begin{abstract}
X-Ray computerized microtomography ( $\mu$-CT) besides providing two-dimensional images (2-D) of the transversal sections of the sample, the biggest attraction of the methodology is the rendering of three-dimensional images (3-D), enabling a more real analysis of the porous structure of the rock. However, the reconstruction, visualization and analysis of such 3-D images are limited in computer terms. Thus, it is not always possible to reconstruct the images with the total size of the microtomographed sample. Therefore, this study aims at determining the Representative Elementary Volume (REV) in reservoir rocks concerning their porosity. In order to collect microtomographic data from reservoir rocks, a microtomograph Skyscan model 1172 was utilized for the sandstone and siltstone samples scanning. After the analysis of the graphs obtained by REV, it was concluded that the most adequate dimensions for the reconstructed volume in each analyzed sample were approximately $1400 \times 1400 \times 1400 \mu \mathrm{m}$, which are dimensions that can easily be reconstructed, visualized and analyzed.
\end{abstract}

Keywords: representative elementary volume, X-ray microtomography, porosity, sandstone, siltstone

\section{Introduction}

X-Ray computerized microtomography $(\mu-\mathrm{CT})$ has been considered a powerful analysis tool for petroleum microstructural rocks ${ }^{1-4}$. In the last years, with the development of new technologies, computerized tomographs (CT) have evolved rapidly as far as spatial resolution and image quality are concerned, going from millimeters to micrometers (microtomographs) and, more recently, nanometers (nanotomographs). This rendered possible the visualization of the internal microstructure of porous materials such as the reservoir rocks studied in this work.

$\mu$-CT provides 2-D images of the transversal section of the samples, thus enabling the characterization of their microstructure. However, in order to use the methodology fully, it is necessary to reconstruct, visualize and process three-dimensional images (3-D), although such procedures are still limited in computer terms. Therefore, it is not always possible to create such images with the desired size. Thus, this work aims the determination of the Representative Elementary Volume (REV) of reservoir rocks concerning their porosity. By definition, REV has to be big enough to represent the characteristics of the sample and as small as possible when compared with its total volume $e^{5,6}$. On the other hand, the determination of a representative elementary volume is a way to better understand the microstructure

*e-mail: jaquiel.fernandes@ifc-videira.edu.br of a given material, which is the first step to link the microstructure properties with its physical properties.

3-D microtomographed images are very important for fluid flowing simulation and permeability determination, as without 3-D images such procedures would be conducted with models created with the Truncated Gaussian method, which uses as a base a petrographic thin section of the sample which, most of the times, does not reproduces a satisfactory model of the real structure of the sample. Therefore, it is highly important to reconstruct 3-D microtomographic images that represent the samples of reservoir rocks as faithfully as possible, so as to obtain results that are as close as possible to reality.

It can be seen in the literature ${ }^{7-9}$ that depending on the considered material and the aim of the analysis, a different property is employed for REV calculations. Although this question has been widely discussed in other fields as bone and fibrous materials, it is not the case of works about reservoir rocks, which are much more heterogeneous and complex. As microtomography methodology achieved resolutions compatible with the study of this kind of rocks, the literature about it increased exponentially. But, until now, almost all of the works in this field ignored the necessity to determine the REV of the sample respect to the property of interest. The porosity and porous size distribution are the focus of this paper, so the REV study will be conducted respect to this property. 


\section{Material and Methods}

The $\mu$-CT methodology is a non-destructive technique that measures density variations in the material. This methodology uses a set of two-dimensional projections of an object to reconstruct its two-dimensional structure and, consequently, the three-dimensional one as well, by using a mathematical algorithm ${ }^{10-14}$. An illustration of the data acquisition, reconstruction and generation of a 3-D image and model is presented in Figure 1.

As seen in Figure 1, the X-ray passes through the sample that will be scanned; those photons are attenuated by scattering and absorption. The basic equation for the attenuation of a monoenergetic beam by a homogeneous material is given by the Lambert-Beer Law ${ }^{15}$ (Equation 1):

$$
I=I_{0} \exp [-\mu x]
$$

where $I_{0}$ and $I$ are the intensity of the incident and transmitted $\mathrm{X}$-rays, respectively, $\mu$ is the coefficient of linear attenuation for the material being scanned, and $x$ is the thickness of the sample to be covered by the beam in the material. As in the majority of the cases the scanned object consists of a different number of materials and the energy of the X-ray tube is polyenergetic, the equation becomes ${ }^{16}$ (Equation 2):
$I=\int_{0}^{E_{\text {máx }}} I_{0}(E) \times \exp \left[-\int_{0}^{x} \mu(E, x) d x\right]$

The two-dimensional and three-dimensional imaging of the reservoir rock samples using $\mathrm{CT}$ and/or $\mu$-CT have become a standard practice in the petroleum industry. In general, water injection is used for petroleum extraction from reservoir rocks and $\mathrm{CT}$ and $\mu-\mathrm{CT}$ techniques are being used to determine important parameters in this process, such as porosity $(\phi)$, pore size distribution and permeability $(k)$.

In the petroleum industry it is very common to use other methods to determine such parameters. The most popular are mercury intrusion porosimetry ${ }^{17,18}$ and the Archimedes method, though the use of such methods renders the utilization of the samples in future analyses unviable because these methods are destructive. On the other hand, the CT and $\mu$-CT techniques, besides enabling future analyses of the already analyzed sample, also provide internal visualization of the sample by means of 2-D and 3-D images.

\subsection{Equipment and software}

A microtomograph Skyscan model 1172 was used, installed at the PETROBRAS Research and Development Center (CENPES), Rio de Janeiro, RJ, Brazil. The microtomographed images were reconstructed by NRecon
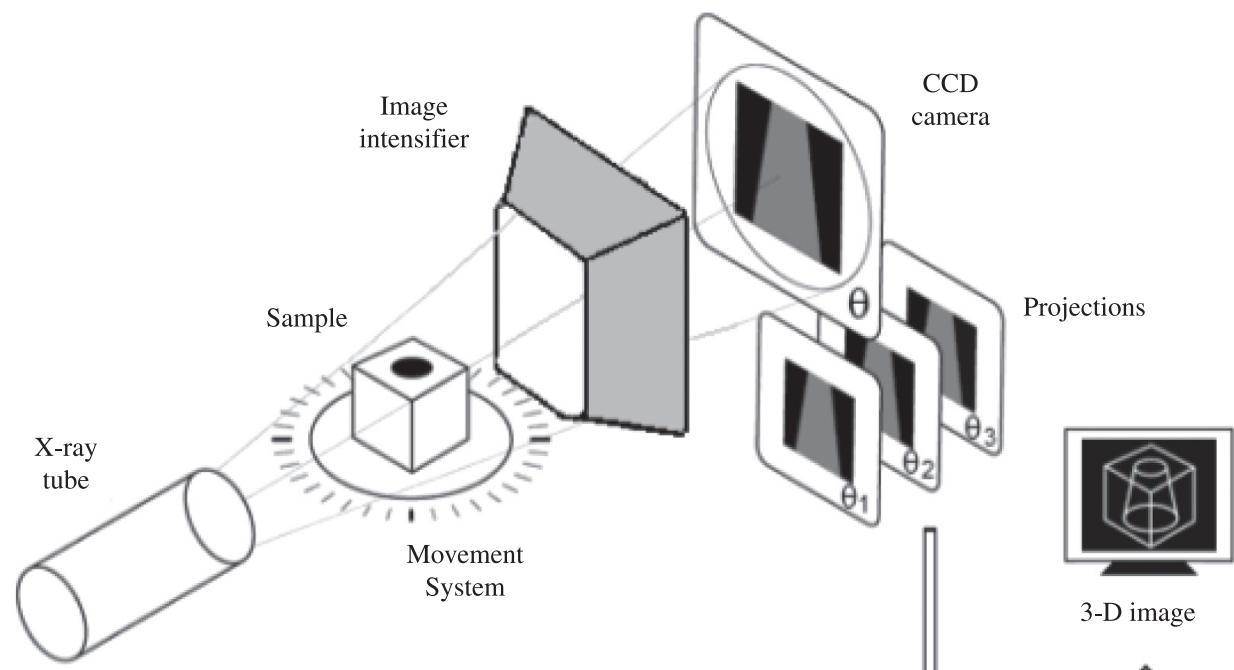

3-D image Analysis of images

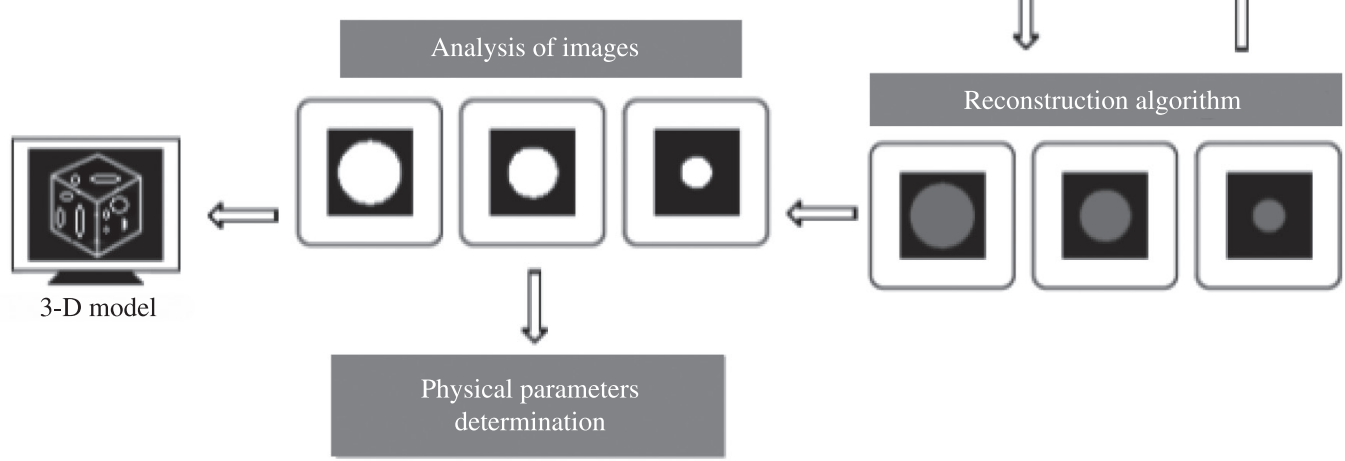

Figure 1. Illustration of the data acquisition, reconstruction and generation of three-dimensional images and models. 
software $^{19}$. The porosity data of the samples were obtained by Imago software ${ }^{20}$, developed at the Laboratory of Porous Means and Thermophysical Properties of Materials (LMPT) from the Department of Mechanical Engineering at Federal University of Santa Catarina, in Florianópolis, SC, Brazil, in association with the Brazilian software company ESSS (Engineering Simulation and Scientific Software). This study also used CTan software ${ }^{19}$ in order to conduct the $3-\mathrm{D}$ reconstructions of the samples. Figure 2 presents a photograph of the microtomograph Skyscan 1172 installed at CENPES.

This microtomograph has an X-ray tube with tungsten anode (W), $10 \mathrm{~W}$ maximum power, $20-100 \mathrm{kV}$ voltage and $0-250 \mu \mathrm{A}$ current. For the detection of the X-rays, a $10 \mathrm{Mp}$ (megapixel) CCD camera was used. The better spatial resolution obtained by this equipment is about $1 \mu \mathrm{m}$ for samples with no more than $5 \mathrm{~mm}$ diameter and $80 \mathrm{~mm}$ high.

\subsection{Analyzed samples}

With the exception of a sample from the Tumblagooda formation, which was extracted from an outcrop at Kalbari National Park in Australia, and provided by

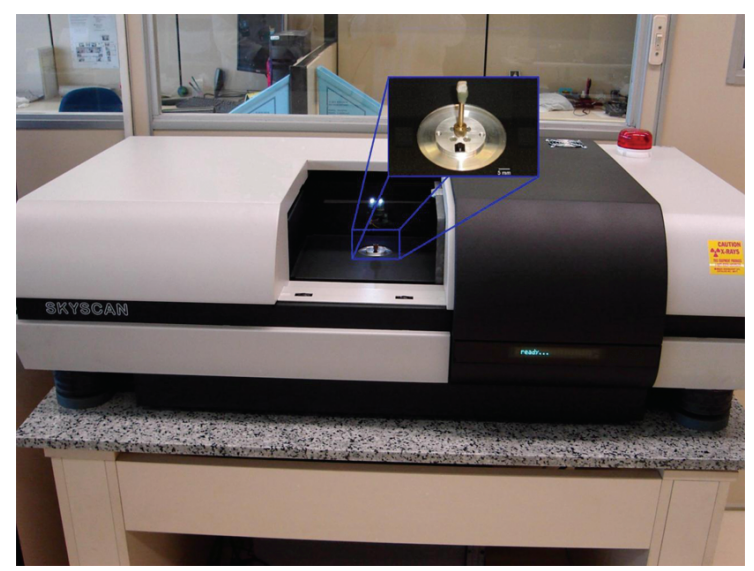

Figure 2. Microtomograph Skyscan 1172, 20 - 100 kV X-ray source, $10 \mathrm{~W}$ maximum power.
CENPES/PETROBRAS, all the other rock samples were withdrawn from the Tibagi River Basin, in the State of Paraná, Brazil21.

Table 1 presents a summary of the rock samples utilized, as well as their group, formation and spatial resolution of the images. Such samples were selected to represent easily analyzable rocks (with wider pores and without clay) and rocks that are difficult to analyze (smaller pores and seldom with clay).

\subsection{Representative elementary volume (REV)}

As the reconstruction, visualization and characterization processes of 3-D images demand high computational capacity, which is very limited up to the present, this work aimed at verifying the REV to determine the porosity of such samples. The REV has to be big enough to contain the elements from the porous media to represent the characteristics of the sample, and as small as possible when compared with its total volume.

REV should be interpreted as a representative portion of the media so that, when selecting such a volume in different regions of the sample, the mean porosity value should not vary significantly. In addition, it was also accomplished the analysis of the REV for the pore size distribution of the samples.

Tests were conducted with several cubic subvolumes: $250 \mu \mathrm{m}, 400 \mu \mathrm{m}, 500 \mu \mathrm{m}, 600 \mu \mathrm{m}, 750 \mu \mathrm{m}, 900 \mu \mathrm{m}$, $1000 \mu \mathrm{m}$, increasing in steps of $100 \mu \mathrm{m}$ till reaching a $2000 \mu \mathrm{m}$-side cube. This procedure was repeated in five different regions of the sample: upper left corner, upper right corner, lower left corner, lower right corner and center of the sample. Figure 3 presents transversal sections of the analyzed samples with the approximate location of the respective five subvolumes. Darker gray (or black) shades represent the porous phase and lighter gray shades represent the solid phase of the sample.

\section{Results}

After obtaining the subvolumes and using, for comparison purposes, the total porosity of each sample, determined by the analysis of all the 2-D images with

Table 1. Main characteristics of the samples utilized.

\begin{tabular}{cccccc}
\hline Sample & Group & Formation & $\begin{array}{c}\text { Spatial } \\
\text { resolution } \\
(\boldsymbol{\mu m})\end{array}$ & $\begin{array}{c}\text { Dimensions of the } \\
\text { sample }(\mathbf{m m})^{\mathbf{a}}\end{array}$ & Description \\
\hline 107 & São Bento & Botucatu & 2.9 & $5 \times 5 \times 15$ & Silicified sandstone \\
108 & Passa Dois & $\begin{array}{c}\text { Rio do } \\
\text { Rastro }\end{array}$ & 2.9 & $5 \times 5 \times 15$ & Siliceous sandstone \\
\hline 403 & Passa Dois & Teresina & 3.9 & $7 \times 7 \times 13$ & $\begin{array}{c}\text { Siliceous sandstone, very thin } \\
\text { lamination, orangish gray }\end{array}$ \\
MC16 & Guatá & Rio Bonito & 2.5 & $4 \times 5 \times 16$ & $\begin{array}{c}\text { Siltstone } \\
\text { PG6 }\end{array}$ \\
Itararé & $\begin{array}{c}\text { Rio do } \\
\text { Sul }\end{array}$ & 2.9 & $\begin{array}{c}\text { Yellow siltstone with engraved } \\
\text { rounded pebbles }\end{array}$ \\
\hline PG19 & Paraná & Furnas & 5.0 & $\begin{array}{c}\text { Thick sandstone with low } \\
\text { granulometric selection level and } \\
\text { presence of muscovite }\end{array}$ \\
\hline Tumblagooda & Dirk Hartog & Tumblagooda & 2.9 & $6 \times 9 \times 20$ & $\begin{array}{c}\text { Thick sandstone with low } \\
\text { granulometric selection }\end{array}$ \\
\hline
\end{tabular}


maximum ROI (selected region of interest in the image), the individual porosity for each of the subvolumes was calculated and the results plotted as shown in Figures 4 to 11 .

By analyzing the graph in Figure 4 as an example, if a $400 \mu \mathrm{m}$-side cubic volume is chosen, the operator may select it in the lower right corner and obtain $11.8 \%$ porosity or, instead, he could choose the lower left corner, thus obtaining approximately $1 \%$ porosity. This means that both volumes would provide a very different porosity value compared to the mean value found for this sample (6.1\%). In this case, the most appropriate would be to use a cubic volume equal or superior to $1200 \mu \mathrm{m}$-size, as any sample region would provide a porosity value close to the mean value.

In Figure 5, as well as in Figure 4, the smaller size subvolumes should not be used for quantitative analysis of the sample, because the $250 \mu \mathrm{m}$-size subvolume located at the lower right corner presents a $240 \%$ difference in relation to the whole sample mean porosity. In this case, the most appropriate would be to use a subvolume equal to or bigger than $900 \mu \mathrm{m}$-size, because with such dimensions the subvolumes in the several sample regions present relatively constant values, though not very close to the mean porosity.

The subvolumes presented in Figures 6, 7, 9, 10 and 11 also showed that the smaller dimensions are not appropriate for analysis, as such subvolumes present great variability. However, dimensions bigger than or equal $1100 \mu \mathrm{m}, 500 \mu \mathrm{m}, 600 \mu \mathrm{m}, 900 \mu \mathrm{m}$ and $1200 \mu \mathrm{m}$, respectively, could be used for quantitative analyses of the porosity of the considered sample.
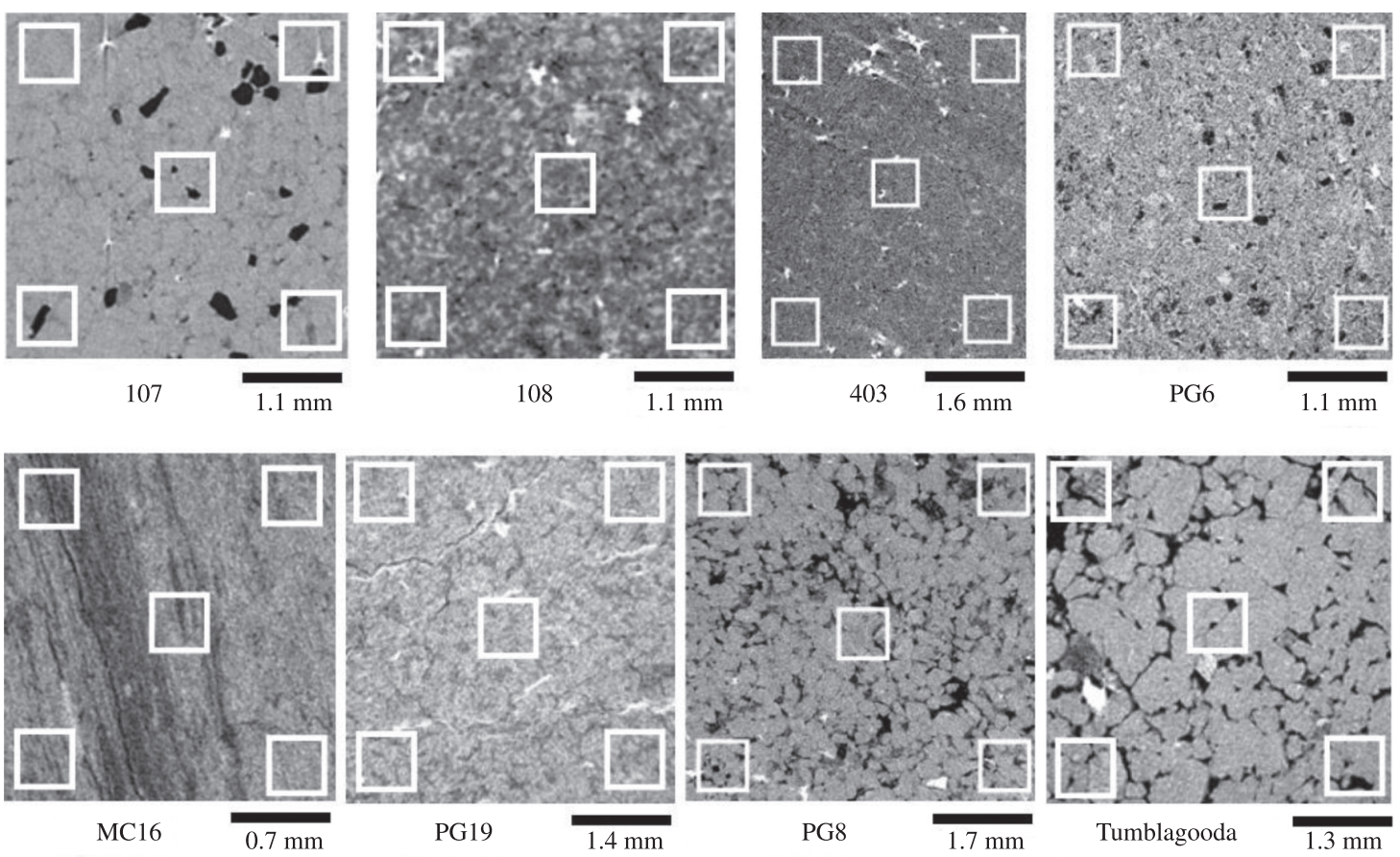

Figure 3. Approximate location of the five subvolumes created for the determination of REV in section 2-D of the samples.

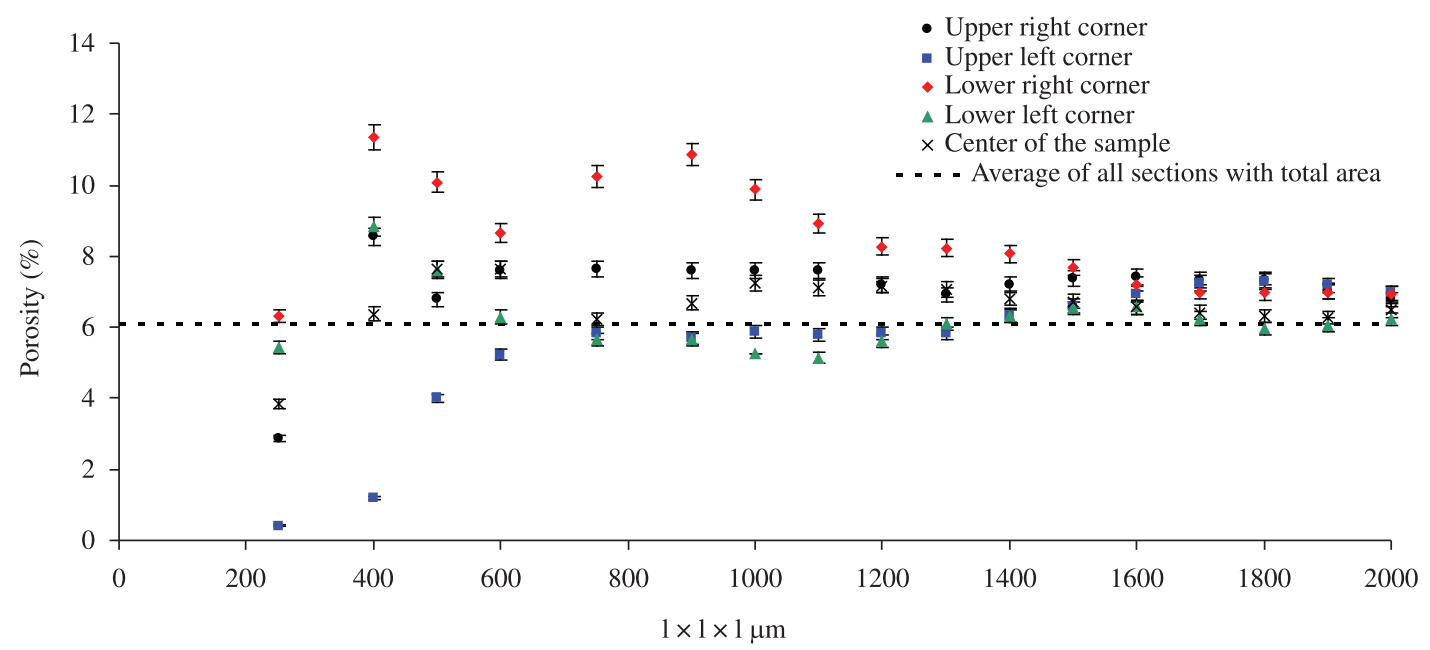

Figure 4. Study of porosity stability with variation of cube length 1 in different regions of sample $107(1 \times 1 \times 1)$. 


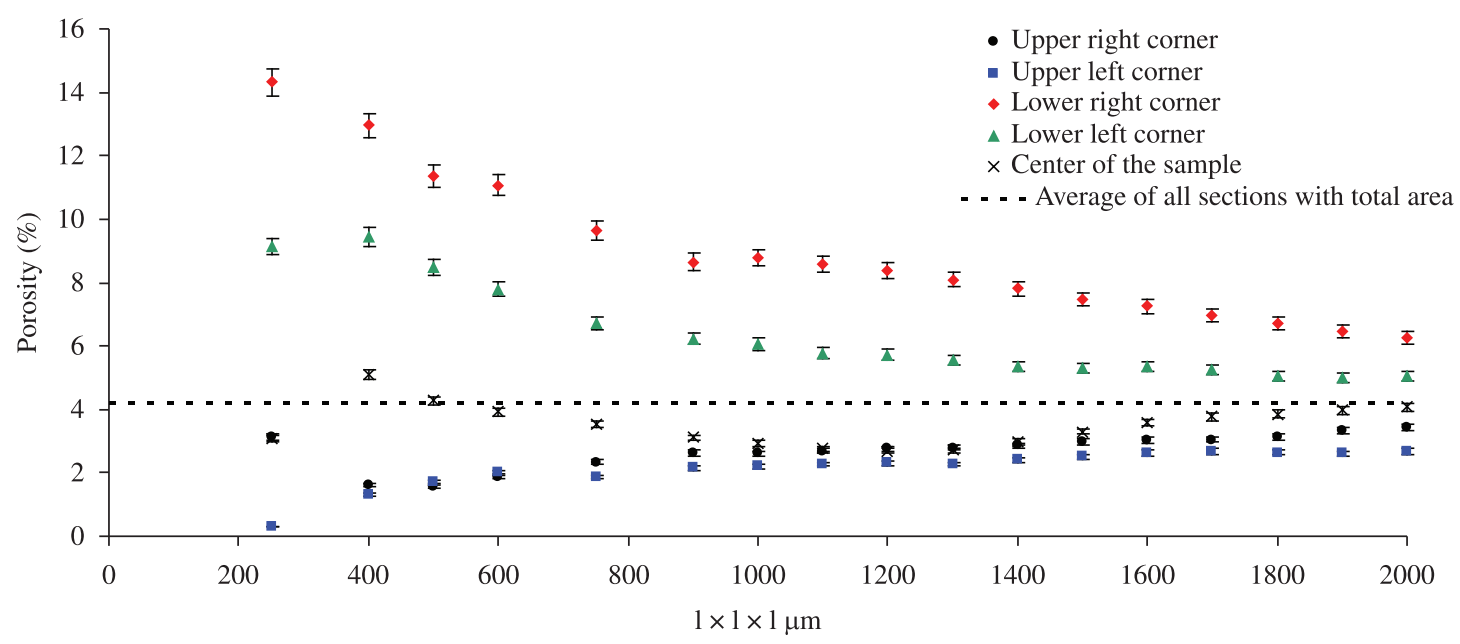

Figure 5. Study of porosity stability with variation of cube length 1 in different regions of sample $108(1 \times 1 \times 1)$.

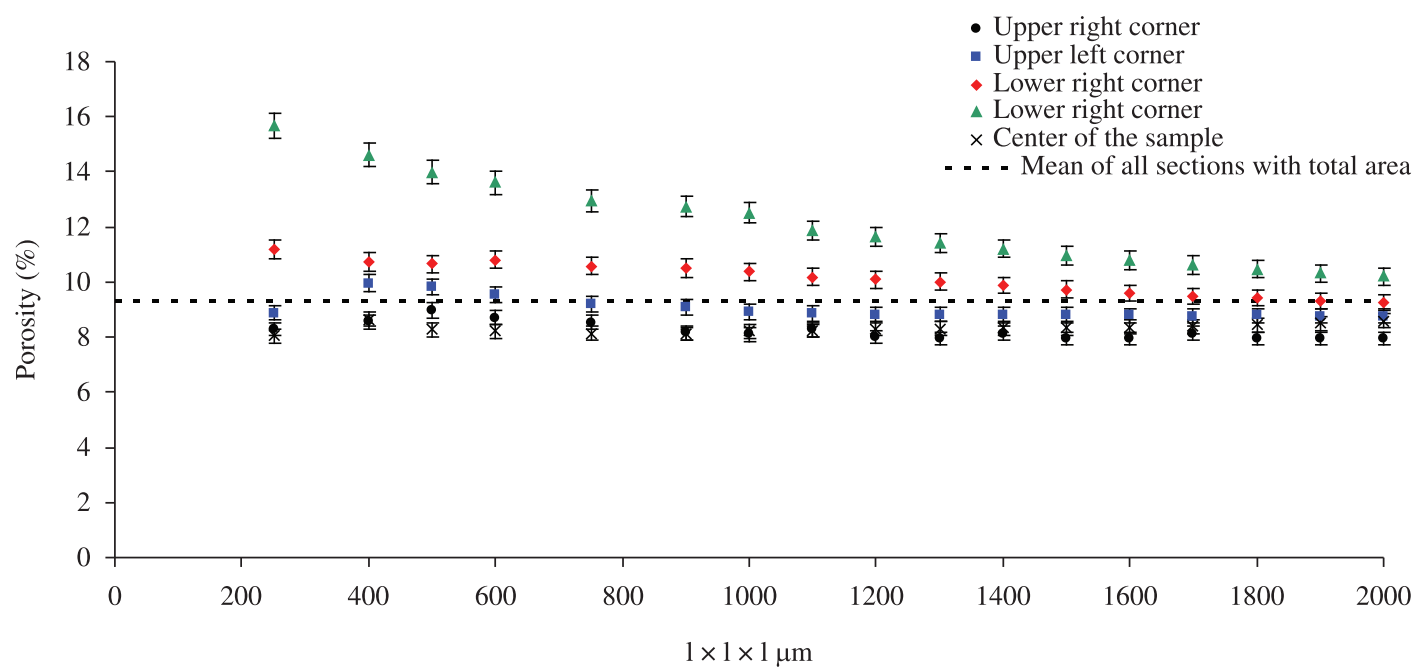

Figure 6. Study of porosity stability with variation of cube length 1 in different regions of sample $403(1 \times 1 \times 1)$.

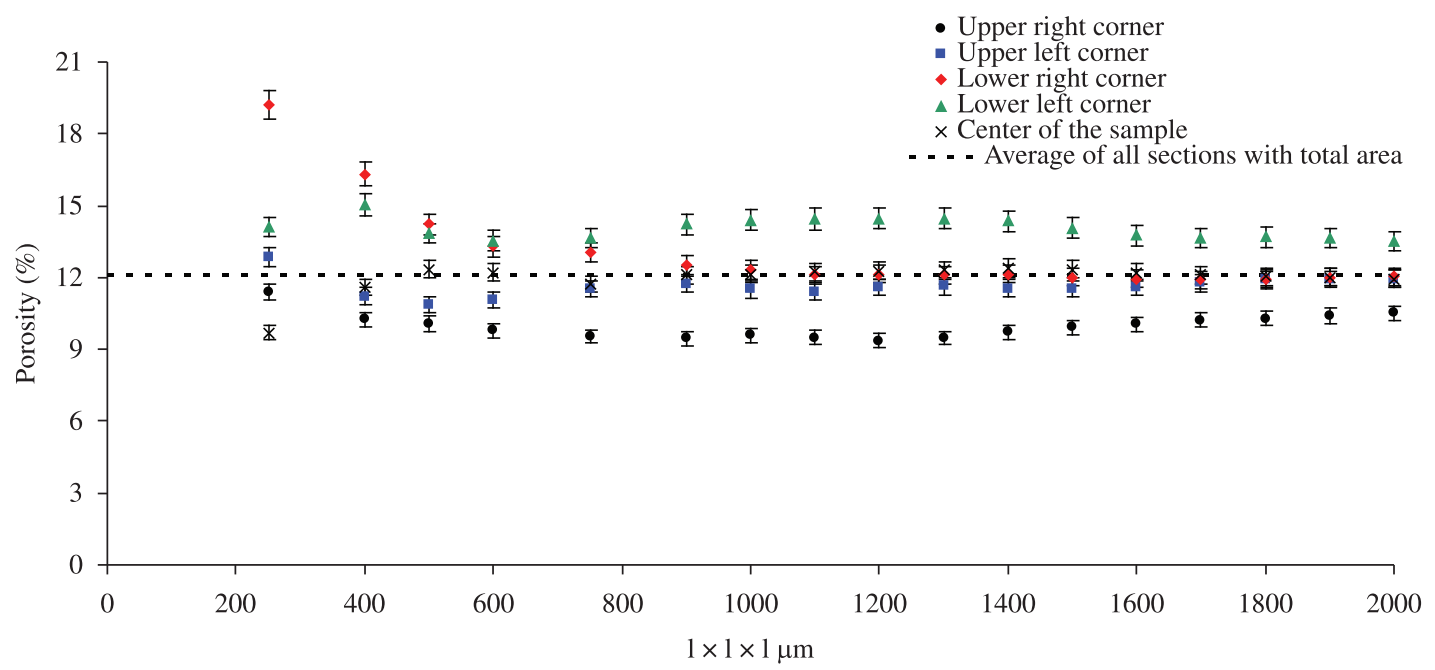

Figure 7. Study of porosity stability with variation of cube length 1 in different regions of sample PG6 $(1 \times 1 \times 1)$. 


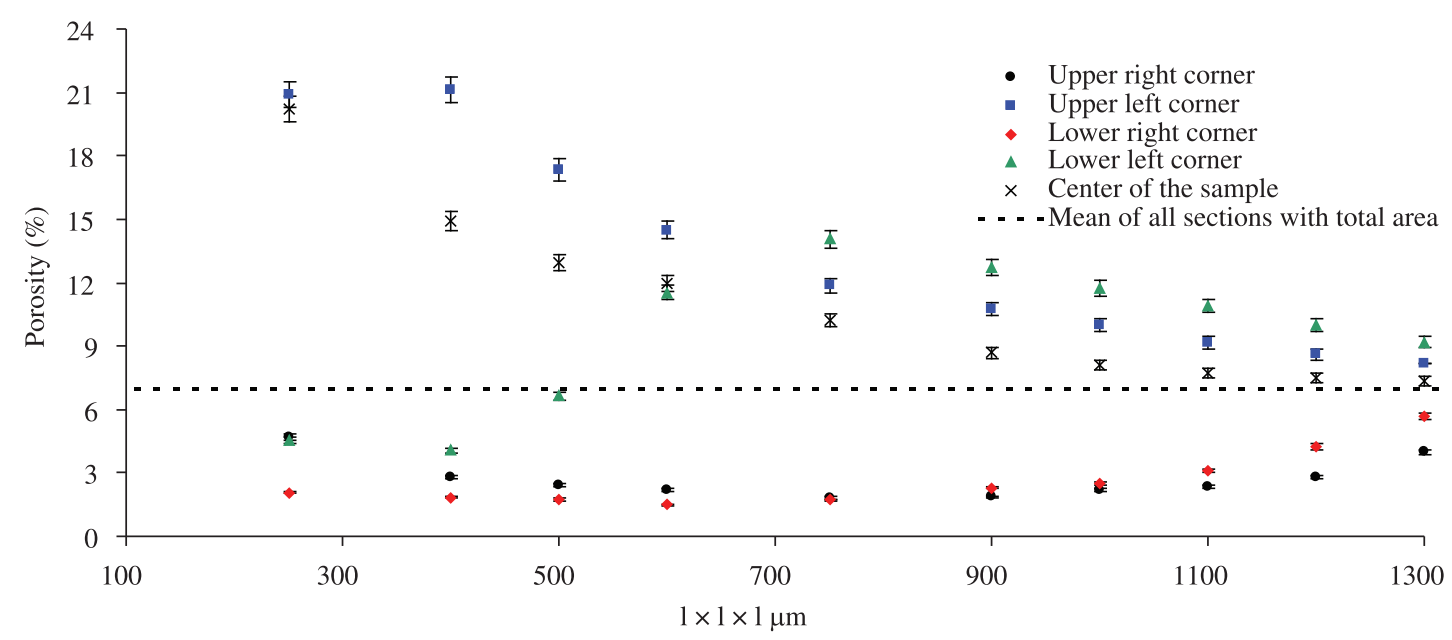

Figure 8. Study of porosity stability with variation of cube length 1 in different regions of sample MC16 $(1 \times 1 \times 1)$.

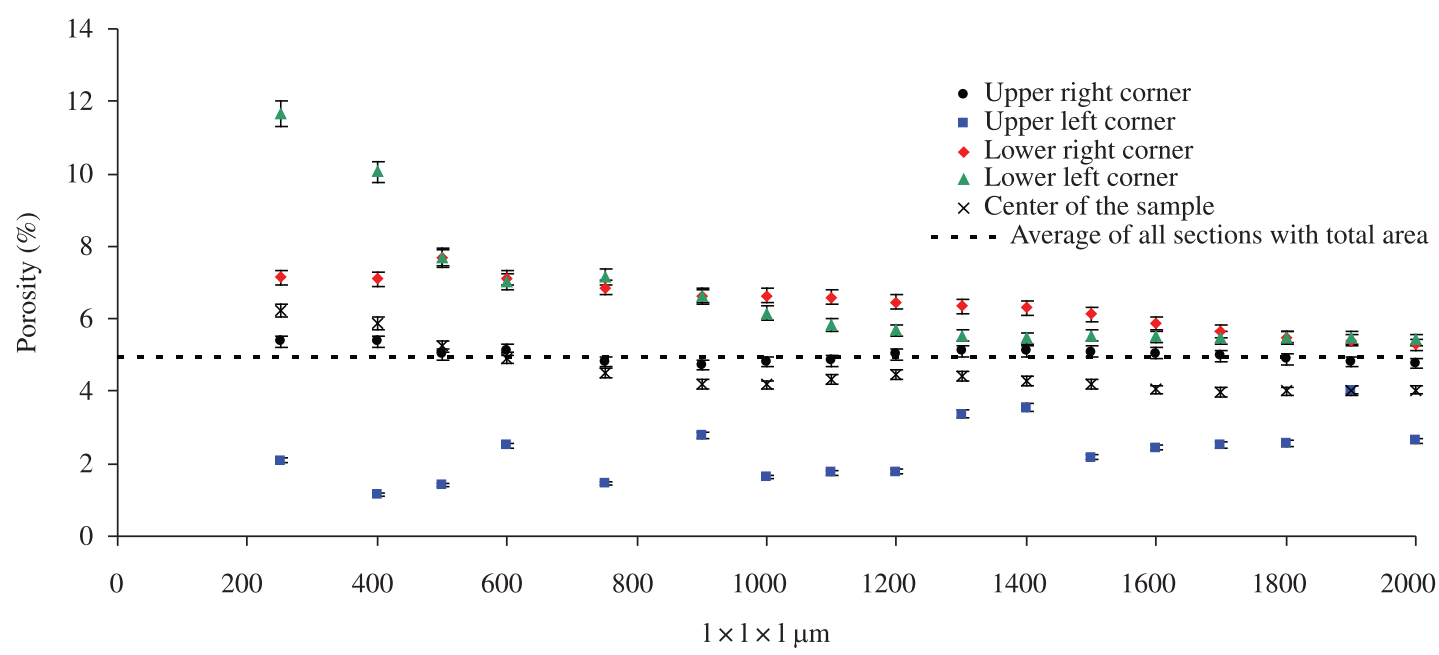

Figure 9. Study of porosity stability with variation of cube length 1 in different regions of sample PG19 $(1 \times 1 \times 1)$.

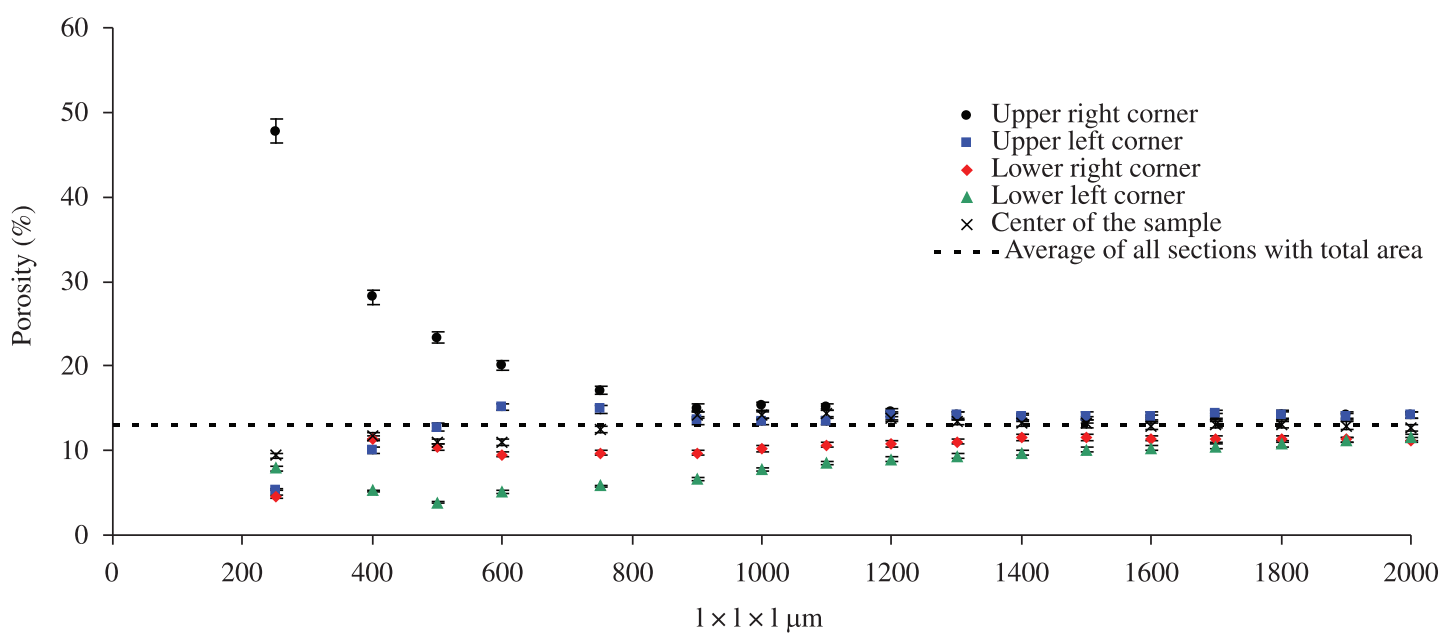

Figure 10. Study of porosity stability with variation of cube length 1 in different regions of sample PG8 $(1 \times 1 \times 1)$. 


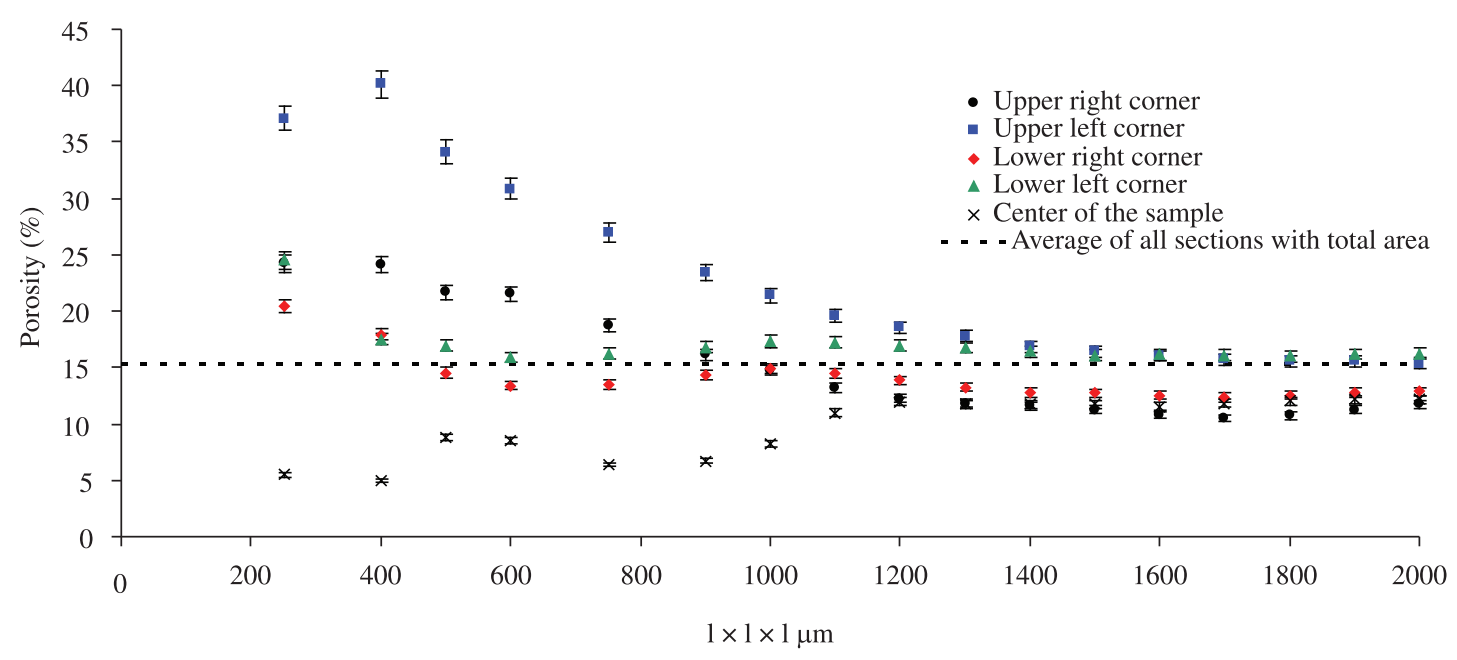

Figure 11. Study of porosity stability with variation of cube length 1 in different regions of sample Tumbladooda $(1 \times 1 \times 1)$.

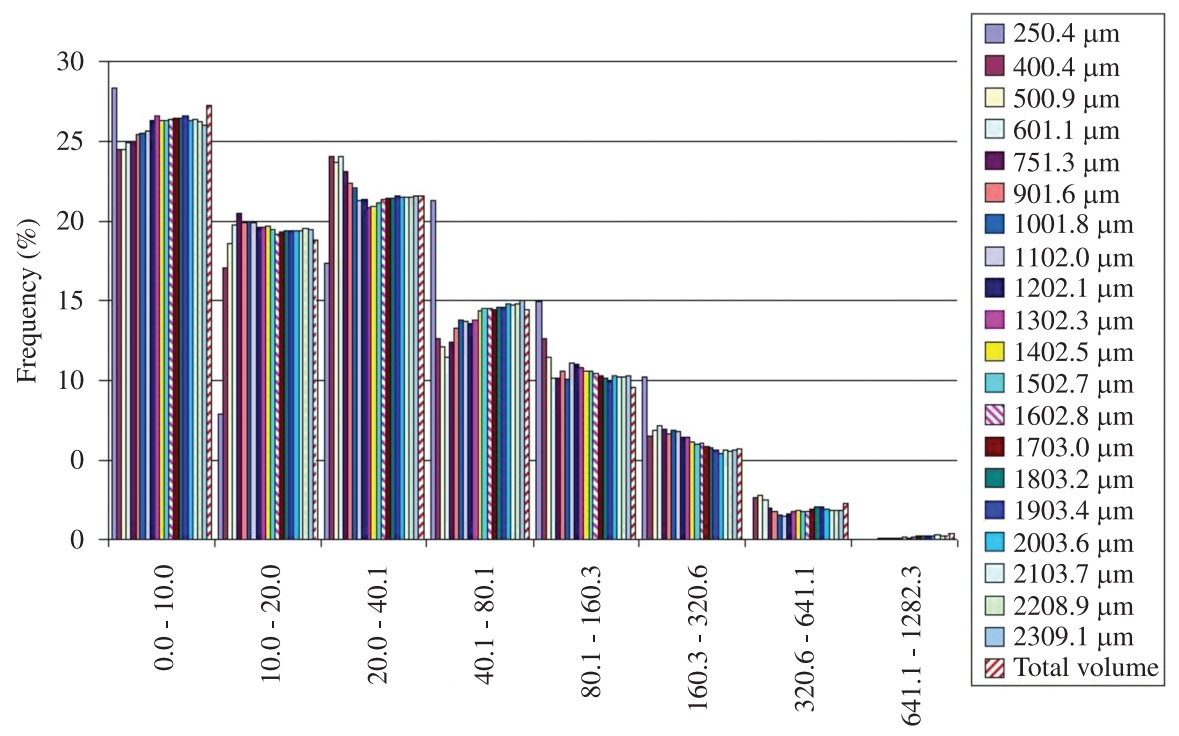

Radius $(\mu \mathrm{m})$

Figure 12. Mean pore size distribution for the subvolumes of the central area of the sample PG8.

The accentuated dispersion for the porosity results of the subvolumes found for siltstone MC16 (Figure 8) is due to the anisotropy of the sample. A fact that can be also observed in its 2-D image presented in Figure 3. For this sample it was not possible to create subvolumes up to $2000 \mu \mathrm{m}$ because its 2 -D section was only $2500 \times 2500 \mu \mathrm{m}$, which would cause the subvolumes to overlap.

After the analyses of the REV graphs, it was verified that, for most of the samples, porosity does not undergo much alteration for cubes with sides bigger than $1400 \mu \mathrm{m}$, presenting approximately constant values for each subvolume. However, it was also verified that what may cause subvolume porosity to vary is its location in the sample (upper right corner, lower right corner, ...) due to possible anisotropy of the sample. Careful analysis of REV plot and the respective image can reveal whether the microstructures of the tested sample has anisotropic properties. Nevertheless, this fact would not affect the reconstruction of an adequate 3-D volume, as the results of the five subvolumes with dimensions superior to $1400 \mu \mathrm{m}$ are relatively similar. The $1400 \mu \mathrm{m}$-side value was considered to comprehend all the samples, though it is possible to observe in Figure 10 (sample PG8) that the REV for this sample would be only $900 \mu \mathrm{m}$.

The computer utilized (Intel quad core i7 processor, 6 GB RAM) to manipulate such images enables the reconstruction of 3-D volumes with maximum $2100 \mu \mathrm{m}$-side. As this computer, at time this work was done, was currently one of the most modern PC, this indicates the limitation in the computational process for the three-dimensional reconstruction of petroleum reservoir rock porous volume.

Figure 12 presents the variability of the mean pore size distribution for the respective subvolumes in the central area of the sample. In this case only the graph of the sample PG8 


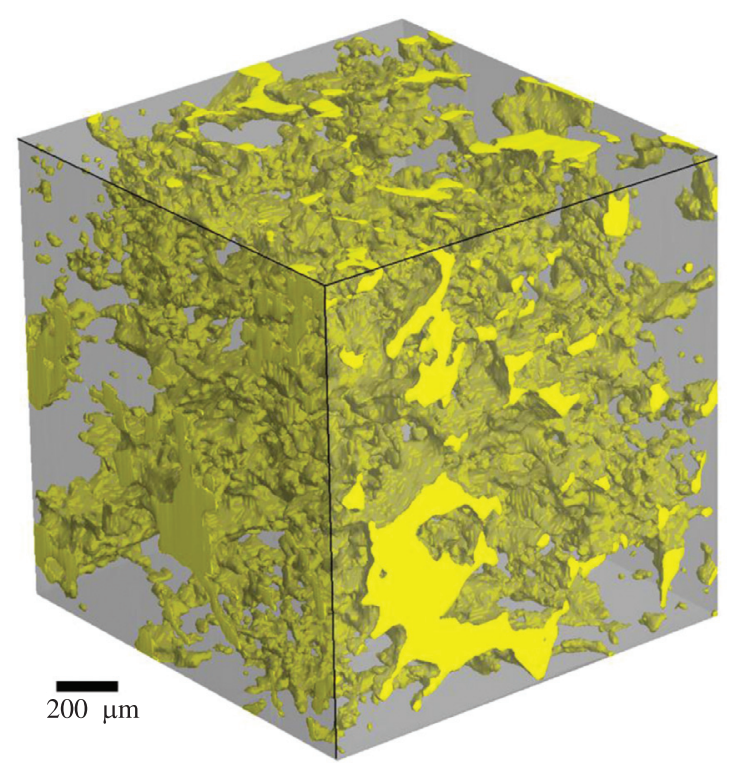

Figure 13. Reconstructed 3-D image of sample PG8 $(1400 \times 1400 \times 1400 \mu \mathrm{m})$ - gray represents the solid phase and yellow the porous phase.

Table 2. Porosity $(\phi)$ calculated for 2-D and 3-D images of the analyzed samples.

\begin{tabular}{ccc}
\hline Sample & $\begin{array}{c}\phi^{\mathbf{1}} \\
\text { Sections } \\
\text { 2-D }(\boldsymbol{\%})\end{array}$ & $\begin{array}{c}\phi^{\mathbf{2}} \\
\text { Image } \\
\text { 3-D }(\boldsymbol{\%})\end{array}$ \\
\hline 107 & $6.1 \pm 0.2$ & $5.4 \pm 0.2$ \\
108 & $4.2 \pm 0.1$ & $4.0 \pm 0.1$ \\
403 & $9.3 \pm 0.2$ & $7.6 \pm 0.2$ \\
MC16 & $7.0 \pm 0.2$ & $6.5 \pm 0.2$ \\
PG6 & $12.0 \pm 0.3$ & $11.5 \pm 0.2$ \\
PG8 & $13.0 \pm 0.2$ & $12.6 \pm 0.2$ \\
PG19 & $4.9 \pm 0.1$ & $5.1 \pm 0.1$ \\
Tumblagooda & $15.3 \pm 0.5$ & $13.4 \pm 0.4$ \\
\hline
\end{tabular}

${ }^{1}$ Total mean porosity with $95 \%$ confidence. ${ }^{2}$ Porosity for REV $(1400 \times 1400 \times 1400 \mu \mathrm{m})$ with $95 \%$ confidence.

was presented, therefore, except for the sample MC16 which has great heterogeneities, all the other samples presented the same characteristics. In this figure it can be observed that the same subvolumes of REV used for the determination of the porosity is also applied, once the distribution for the subvolumes with dimensions of $1400 \mu \mathrm{m}$ presents values approximately constant and very close to that of the total volume.

Table 2 shows a comparison of the porosity values for the 3 -D volume dimensions $1400 \times 1400 \times 1400 \mu \mathrm{m}$, selected at random in the central region of the sample, with mean porosity determined for all the 2-D sections with total ROI. This table also shows that such values are in perfect accordance, which is mostly due to the Representative Elementary Volume (REV) analyses that determined the ideal volume for the 3-D images to be representative of the sample as a whole.

As an example of the reconstructed volumes according to the dimensions determined by the REV graph analysis,
Figure 13 shows the 3 -D reconstructed volume of sample PG8, in which yellow represents the pores and gray represents the solid phase of the sample.

\section{Conclusions}

The determination of a representative elementary volume is a way to better understand the microstructure of a given material, which is the first step to link the microstructure properties with its physical properties.

This study determined the Representative Elementary Volume (REV) of eight different reservoir rocks concerning to their porosity. A microtomograph Skyscan model 1172 was employed for the samples scanning, with resulting spatial resolution ranging from 2.9 to $5.0 \mu \mathrm{m}$.

Apart from siltstone MC16, which displays very heterogeneous pore distribution, due to the existing lamination in the sample, all the other analysed samples presented results indicating that $1400 \mu \mathrm{m}$-side subvolumes have porosity that is representative of the sample total volume, which can be observed, in Table 2 , in the excellent agreement between the porosity value determined by the 2-D images and the 3-D volume obtained according to the dimensions determined by REV criteria. Such dimensions are easily reconstructed, visualized and analyzed. The $1400 \mu \mathrm{m}$-side value was considered adequate for all samples, though it is possible to observe at Figures 4 to 11 that REV is different for each kind of sample and, for example, for the sample PG8 it would be only $900 \mu \mathrm{m}$.

\section{Acknowledgments}

This work was partially funded by CAPES/PROCAD, PETROBRAS Research and Development Center, Federal University of Santa Catarina and State University of Londrina. 


\section{References}

1. Coles ME, Hazlett RD, Spanne P, Soll WE, Muegge EL and Jones KW. Pore level imaging of fluid transport using synchrotron X-ray microtomography. Journal of Petroleum Science and Engineering. 1998; 19:55-63. http://dx.doi. org/10.1016/S0920-4105(97)00035-1

2. Rosenberg GE, Ferreira de Paiva R, Guéroult P and Lynch J. Microtomography Applications in Rock Analysis and Related Fields. In: Proceedings of the Deutsche Gesellschaft für Zerstörungsfreie Prüfung - DGZfP; 1999; Germany. Germany; 1999. p. 9-18.

3. Appoloni CR, Rodrigues $\mathrm{CRO}$ and Fernandes CP. Porous microstructure characterization of a sandstone reservoir using high-resolution X-ray microtomography. In: Proceedings of the International Symposium of the Society of Core Analysts; 2005; Toronto, Canada. Toronto; 2005. p. 21-25.

4. Appoloni CR, Fernandes CP and Rodrigues CRO. X-ray microtomography study of a sandstone reservoir rock. Nuclear Instruments and Methods in Physics Research A. 2007; 580:629-632. http://dx.doi.org/10.1016/j. nima.2007.05.027

5. Kanit T, Forest S, Galliet I, Mounoury V and Jeulin D. Determination of the size of the representative volume element for random composites: statistical and numerical approach. International Journal of Solids and Structures. 2003; 40:3647-3679. http://dx.doi.org/10.1016/ S0020-7683(03)00143-4

6. Kanit T, N'Guyen F, Forest S, Jeulin D, Reed M and Singleton $\mathrm{S}$. Apparent and effective physical properties of heterogeneous materials: Representativity of samples of two materials from food industry. Computer Methods in Applied Mechanics and Engineering. 2006; 195:3960-3982. http://dx.doi. org/10.1016/j.cma.2005.07.022

7. Cheng Q, Muszynski L, Shaler S and Wang J. Microstructural changes in wood plastic composites due to wetting and re-drying evaluated by X-ray microtomography. Journal of Nondestructive Evaluation. 2010; 29:207-213. http://dx.doi. org/10.1007/s10921-010-0078-0

8. Mendoza F, Verboven P, Mebatsion HK, Kerckhofs G, Wevers $\mathrm{M}$ and Nicolaï B. Three-dimensional pore space quantification of apple tissue using X-ray computed microtomography. Planta. 2007; 226:559-570. PMid:17361459. http://dx.doi. org/10.1007/s00425-007-0504-4

9. Rolland du Roscoat S, Decain M, Thibault X, Geindreau C and Bloch J-F. Estimation of microstructural properties from synchrotron X-ray microtomography and determination of the
REV in paper materials. Acta Materialia. 2007; 55:2841-2850. http://dx.doi.org/10.1016/j.actamat.2006.11.050

10. Cormack AM. Representation of a Function by Its Line Integrals, with Some Radiological Applications. Journal of Applied Physics. 1963; 34:2722-2727. http://dx.doi. org/10.1063/1.1729798

11. Cormack AM. Representation of a Function by Its Line Integrals, with Some Radiological Applications. II. Journal of Applied Physics. 1964; 35:2908-2913. http://dx.doi. org/10.1063/1.1713127

12. Feldkamp LA, Davis LC and Kress JW. Practical cone-beam algorithm. Journal of the Optical Society of America A. 1984; 1:612-619. http://dx.doi.org/10.1364/ JOSAA.1.000612

13. Flannery BP, Deckman HW, Roberge WG and D'Amico KL. Three-Dimensional X-ray Microtomography. Science. 1987; 237:1439-1444. PMid:17816787. http://dx.doi. org/10.1126/science.237.4821.1439

14. Wellington SL and Vinegar HJ. X-Ray Computerized Tomography. Journal of Petroleum Technology. 1987; 39:885-898. http://dx.doi. org/10.2118/16983-PA

15. Siegbahn K. Alpha-, Beta- And Gamma-Ray Spectroscopy. Amsterdam; New York; Oxford: North-Holland Publishing Company; 1979. p. 37-76.

16. Kalender WA. Computed Tomography - fundamentals, system technology, image quality, applications. 2nd ed. Publicis Coporate Publishing; 2005.

17. Webb PA and Orr C. Analytical methods in fine particle technology. Norcross: Ed. Micromeritics Instrument Corporation; 1997.

18. Johson R, Abrams L and Maynard RB. Use of mercury porosimetry to chracterize pore structure and model end-use properties of coated papers. Tappi Journal. 1999; 82:239-251.

19. Skyscan. Two-dimensional and three-dimensional reconstruction software. Available from: <http://www.skyscan. be/products/downloads.htm>. Access in: 10/11/2010.

20. Imago. Images analysis software. Available from: <https:// www.esss.com.br/index.php?pg=viewprojeto\&idProject=9>. Access in: 10/11/2010.

21. Empresa de Pesquisa Energética - EPE. Avaliação ambiental integrada dos aproveitamentos hidrelétricos da Bacia do Rio Tibagi. Available from: <http://www.epe.gov.br/ MeioAmbiente/Documents/MeioAmbiente_13/SemináriosPúb licosparaDiscussãodoTermodeReferênciaAAI-parte2-12-2008. pdf>. Access in: 10/01/2011. 